\title{
A Framework adressed to the increasing cases of resistance and non adherence due to disclosure difficulties among hiv patients
}

\section{Gift Arnold MUGISHA}

Uganda Martyrs Secondary School Namugongo

Abstract:Disclosure in the medical world is a proving catastrophy, unadressed may catalyse extinction of human genome.The world over has evidenced the wrath that drug resistance can punch into our medical fortresses. The toxic chemicals that once were our powerful remedies against the of late resistant strains,"the superbugs as we know it,"have rendered research a perpetual practice that have left our economies dwindling. In Subsaharan Africa,lives have been lost due to resistant HIV strains and more are on the verge.This paper reports on a programme that is aimed at proving a solution to disclosure related cases and improving adherence patterns among diverse populations by taking into use of scalability and adaptability of a system conceived to foster effectiveness of therapeutic procedures. 